tile steamships-given in the belief that much more is sure to be gained as the ship inclines (within large limits) -has resulted in the capsizing of many ships at sea, and in grave danger to many that are still afloat, not in the same manner, because not in the same condition as to lightness as the Hammonia and Daphne, but from other not less real deficiencies." Sad and serious as this statement is, I repeat it here with perfect confidence in its accuracy.

Sometimes such vessels are brought into a condition of apparent safety by the stowage of their own coal, but as the coal is consumed their stability diminishes, they capsize, disappear, and the word "missing" is recorded against them in an official return. No means exists, notwithstanding all our shipping legislation, for insuring that the facts will be brought to light--indeed, at the official inquiry which follows under the present conditior.s, the question of stability may not even be mentioned. As the stability of a ship is often an intricate matter which can be effectually controlled only by close and careful calculation, and,as no Government department is at present charged with the duties even of collecting, recording, and making known those dimensions and particulars of ships which determine their stability, the matter must be left to right itself. Maritime ships of small stability incur dangers from, and are doubtless lost by, the operation of causes which are but very imperfectly appreciated.

It is under the urgent pressure of a very rapidly growing mercantile steam marine that the shipbuilding trade has somewhat, I fear much, outrun the companionship and regulation of science. It is only quite recently that the necessity for developing their scientific staff and appliances has been borne in upon the minds of shipbuilders. There never, even yet, has been so much as a training school or college established by them for the education of young naval architects and draughtsmen throughout the country. But the Admiralty have had their dockyard schools at work for nearly forty years; school after school of Government naval architecture has been established; the Institution of Naval Architects has been formed, and done invaluable work, for more than twenty years; and some private shipbuilders have at length entered with spirit and enterprise upon the labour of developing the practice of scientific naval architecture. No part of my duty in connection with the Daphne inquiry has been so agreeable to me as that of bearing witness to the admirable efforts of several Clyde firms in this respect; and there is no result that can follow from the inquiry which I should esteem so highly as the emulation of their efforts throughout our shipbuilding establishments generally--unless, indeed, it were that of a general awakening of shipowners to their great and enduring responsibilities in this matter.

EDWARD J. REED

\section{INTERNATIONAL POLAR RESEARCHES}

$A^{T}$ the present moment, when every student of modern science is anxiously awaiting the result of the labours of the international observation parties which have for nearly a year been self-imprisoned around the Pole, I venture to make the following suggestions relating to international Polar researches.

The state of the ice in the Arctic seas is, as is generally known, very changeable during various seasons. It is thus impossible beforehand to draw conclusions as to the probable state of the ice one summer by its state the year before, and this circumstance has greatly impeded active researches in the Arctic regions. From time to time valuable and expensive expeditions have been despatched, but these have in most instances been unfortunate enough to encounter the adverse seasons, and the purely geographical gain has in consequence not been in proportion to the cost. At other seasons, on the other hand, when the ice seems to have promised a far advance northwards there has not been any expedition ready to take advantage of the circumstance. Had there at certain times and seasons been expeditions prepared to use the opportunities which have presented themseives, and in the right locality, I have not the least doubt that a very far advance into unknown Polar regions might have been made at a very small cost. In spite of the, in many rerespects, exceedingly valuable discoveries which have resulted from these expeditions to geology, meteorology, and other modern sciences, they seem certainly on the whole as if they had been started under an unlucky star, which is, in my opinion, caused by the circumstance that the period and season selected have not been the proper ones. What we have thus gained has generally been obtained with great loss of time, money, and valuable lives. A most remarkable contrast to this is, however, the voyage of the $V e g a$, which from beginning to end seemed to have been attended with success only, as the forced wintering, when having practically accomplished its object, only tends to heighten the charm of this venture.

From the experience we have gained of the changes in the ice, it is however evident that Polar researches have hitherto, in one respect at all events, been effected in an erroneous manner, and great loss of money and life caused thereby. The geographical researches around the Pole should in my opinion be conducted in a different manner. Instead of, as has hitherto been the case, that finely equipped expeditions are despatched at random and at unconsidered periods, an arrangement should be made between the various European nations to equip a certain number of expeditions, which should be despatched every summer to the same locality during a period of ten to eleven years. During a period of this length it is probable that the conditions of the ice, which we may assume undergo periodical changes, have run their cycle, and during certain years of such a period opportunities would undoubtedly occur which would enable a very far penetration into the Polar basin.

The expenses attending such expeditions would, if skilfully arranged, not exceed those of one of the costly
ones which have hitherto been despatched, while they would not result in the great loss of life which seems to attend the larger one or two years expeditions under which ambition naturally leads the members to venture on any undertaking which may give returns equivalent to the expectations of the equippers.

Hitherto the Dutch alone have arranged their expeditions to the Polar regions in a systematic manner. They have, as is generally known, for some years regularly despatched an expedition every summer to the regions around Spitzbergen and Novaya Zemlya; but that they have not, geographically, obtained any great results may be ascribed to the circumstance that they have employed sailing vessels instead of steamers. Neither have they in all probability laid special stress on geographical achievements in these parts; the expeditions hitherto despatched may thus be considered as mere pioneering ones. From next year it is, however, the intention of the Dutch to employ a steamer instead of a sailing vessel, and then their researches will, no doubt, be more fruitful.

It is now admitted by every student that Polar researches are of great importance in several respects, and the establishment of the international circumpolar stations is a proof of this, while the manner in which these have been arranged seems to promise to be the first step towards a series of researches in the Arctic regions, which would, as the meteorological ones, be best carried out through an international cooperation. In order to advance in the unknown Polar basin, it appears to me to be essential to abandon the random expeditionary attempts hitherto persevered with, and organise instead systematic researches. And if these are carried out by international 
cooperation, the levy on the individual participators would be very small indeed.

There are in my opinion three points in the Arctic seas which offer, I believe, special advantages as bases for penetrating towards the Pole, and on which particular attention should be concentrated, viz. the north of Spitzbergen, the north-east of Novaya Zemlya, and the Behring Straits.

To the north of Spitzbergen, i.e. to the north of the Seven Islands, Norwegian hunters have, in the autumn of certain years, found the sea to the north and north-east so free from ice that they have deemed it a very easy matter to have penetrated with a steamer considerably northwards. Such was, for instance, the state of the ice in the autumn of $188 \mathrm{I}$. And similarly the sea to the north-east of Novaya Zemlya has in certain years been easy of navigation, and finally, judging by researches, it may be assumed that the same is the case with the sea north of the Behring Straits.

Now, in order to carry out the programme which I have here suggested for a more systematic research of the Polar regions, I advocate that four small but excellent steamers should be provided, of which one should every year be despatched to a station on the north coast of Spitzbergen, another to one at the northern point of Novaya Zemlya, and the remaining two to respective stations north of the Behring Straits. This should be carried out during eleven consecutive years. Then when the state of the ice in certain seasons was very favourable, the vessels should take advantage of the opportunity and proceed northwards.

The advantage of this plan is that it would be attended with very little ris', while the object should be not to attempt to force an advance, but rather to wait patiently until the favourable opportunity presents itself, and then to act with boldness and decision. There is on the other hand every reason to assume that the time of the members of these expeditions would be employed throughout in a way beneficial to science. As a matter of safety it would also be advisable to establish fixed stations or depots in suitable places, to which the expeditions could resort in case of need.

From the experience we have gained of late it may be safely assumed that the Polar basin is not during any whole sum ner or autumn covered with continuous ice; it is in fact evident that the sea shows large tracts of open water during these seasons. The ocean ice north of Spitzbergen is thus always in a constant-at times even exceedingly violent-state of drifting in the most varied directions, according to the currents and winds prevailing. At ti nes, too, the ice has been found to drift in a direction contrary to those of currents and winds. North of Spitzbergen there must, therefore, during certain periols of the season be large tracts of open water which are capable of receiving the enormous ice masses in drift.

As is generally known, Petermann advanced the hypothesis that Greenland extended in a more or less broad belt of land towards the Pole, from whence it diverged downward; to Behring Straits. If this is so, the great Polar basin should be divided into two parts with a common oxtlet into Behring Straits, although distinctly sepurated from each other by the land belt in question. They would at the other end discharge themselves into two different channels, viz. one in Baffin's Bay and the other in the Greenland and East.Spitzbergen oce an. This hypothesis has been supported by many eminent savants, as for instance Parpart, Jäger, and Chavanne.

Without, howerer, disputing the correztness of the reason; for this assumption, it. would no: be difficult to point out circunstances which would refute the hypothesis. And although several things seem to corroborate the aisunption that the real Pular basin contains a belt of smaller and laryer islands, it is perfectly obvious that the climatological and consequently the glacial conditions of these regions would have been quite different from those now prevailing had a large continent of the kind described by Petermann occupied the greater portion of the central Polar basin. I myself believe, judging by the strong motions of the ice north of Spitzbergen and Novaya Zemlya, and certain circumstances attending the same, that the climate of the Polar regions is a sea or insular climate rather than a continental one. In making this assertion, however, I do not say that a continent such as that referred to has not existed there in the Tertiary or early part of the Quaternary period.

However this may be, the question to be solved is one of preeminent importance to men of science, and I feel certain that a mode of research effected in the manner I have here advocated would certainly result in its solution.

Tromsö Museum, July

\section{NOTES}

A meeting of the General Committee of the International Fisheries Exhibition was held at South Kensington on Tuesday. Mr. Birkbeck presided, and read the Report of the Executive Committee, which stated that the number of visitors to the Exhibition has, up to the present, been very large. The numbers up to Saturday, ${ }^{-}$the $25^{\text {th }}$ inst., were $1,444,515$, showing a daily average of 16,050 . The juries have, with few exceptions, now completed their lxbours, and their reports will be laid before the Special Commissioners, appointed by Her Majesty's Government, for consideration and approval. The Rejort closes as follows:- "With regard to the future, it is indispensable that the Executive Committee should obtain the necessary powers from the General Committee to announce the closing of the Exhibition on some day to be fixed hereafter, and that they should further be invested with authority to carry out any negotiations and make any agreements they may deem necessary for the subsequent utilisation of the building, which have been erec:ed at so great a cost, in order that a fair proportion of the money that has been expended upon them may be recsvered. In furtherance of the latter object, the Executive Committee have much pleasure in stating that they have received from Her Majesty's Commissioners of $185 \mathrm{I}$ an intimation that, provided the grounds are used solely for the purposes of holding exhibition;, they wuld be willing to extend the existing agreement (which expires on De. cember 3 I next) for a further periot of three years. The Executive Committee have every reason to believe that, with the approval of the Prince of Wales, exhibitions of great importance will be held in each of these years. Under the se arrangements the authoritie;, which His Royal Highness may be pleased to constitute for carrying out each of these exhibitions, will become tenants of the Fisheries Exhibition, and w uld accordingly pay a proportion of the original cost as rent for the use of the build. ings, The Chair nan said it was a matter of congratulation that the numbers ad nitted $h$ id proved to exceed the $m$ sst sanguine expectations of the general public, and the Committee hat every reason to believe that for the future, especially duriag the month of September, large numbers of visitors would attenl. The most important po:tion of the Report referred to the fature $u$ se of the buildings. Next year it was proposed to holl a great international exhibition of horticulture, floriculture, and forestry, and they hat every reas on to belizve it would be successfal. Thre had been some question of the conferences being continued later on. The discussion on the paper by the Duke of Edinburgh was adjurned sine die, and probably, if $\mathrm{H}_{1 \mathrm{~s}} \mathrm{R}$ oyal Highness was in Lond on at the end of Septe absr or the beginning of $\mathrm{O} s \mathrm{t}$ sber, he might $\mathrm{b}=\mathrm{d}$ isposed to atte.1d. There $\mathrm{w} . \mathrm{s}$ also an ther promise given that there should be a fishermen's 